\title{
Investigation on Joining AISI 304 Stainless Steel by Resistance Spot Welding
}

\author{
J. Pradeep Kumar ${ }^{1}$, Jose V. Eapen ${ }^{2}$ \\ \{jpk.prod@psgtech.ac.in ${ }^{1}$, joseveapen2008@gmail.com ${ }^{2}$ \} \\ Department of Production Engineering, PSG College of Technology, Coimbatore-641004 ${ }^{1}$
}

\begin{abstract}
Electric resistance spot welding is a state of the process of joining metallics for a number of industrial and home purposes. Because of its better corrosion resistance, stainless steel is employed. The strength of a spot weld is determined by a variety of process variables. An experimental research of electric resistance spot welding of austenitic AISI 304 commercially available stainless steel is presented in this work. Welding current, welding time, and electrode diameter were all taken into account. The welded specimens were prepared based on ISO 14273:2001 standard. The Taguchi L9 orthogonal array was employed for ERSW experiments. The influence of process factors on tensile load was investigated using analysis of variance (ANOVA). Based on the study it was found out that welding current influences the tensile load significantly followed by welding time and electrode diameter.
\end{abstract}

Keywords: ERSW, Taguchi's DOE, AISI 04, ANOVA.

\section{Introduction}

In, Electric resistance spot welding (ERSW) heat is generated by the work material's confrontation to the passage of electric current in a circuit of which the work is a part, along with the application of pressure, causes coalescence. One of the distinguishing characteristics of resistance welding is that it does not require the use of a filler rod or flux. In resistance welding current is obtained from step-down transformer, where the number of primary winding is more than that of secondary windings. Hence the output is a low voltage high current supply. The selection of several process factors such as current required for welding, time to weld, and conductor diameter, among others, determines the joint strength. Typically, process conditions are chosen based on professional practice or from meta data available welding handbooks. However, the levels of process parameters may vary in different spotwelding machines based on its machine specification.

\section{Literature Review}

Prasanthkumar V K [1] conducted an experimental investigation for determining the resistance spot welding process conditions for joining $2 \mathrm{~mm}$ thick CRCA sheets. The effect of current required to weld and time to weld were studied on joint strength. The thermal analysis has been done using SYS weld software. A full factorial Design of Experiment (DOE) has used for conducting the numerical analysis. The tensile load testing conducted with the help of universal testing machine. The strength of the weld joint was determined by the load at which 
it broke. The break load is $7.3 \mathrm{kN}$ for the optimum value of current $3928 \mathrm{~A}$ and 0.3 seconds. From simulation they have found that Heat affected zone prevails around $4.5 \mathrm{~mm}$ from the axis of the weld line. Metal sputtering was also observed when the current increased.

In the resistance spot welding (RSW) procedure, Ugur Esme [2] considered the impact of welding sceneries on the strength of the joint due to tension while welding SAE 1010 sheet metallic profiles. Process factors such as force applied by the conductor, current required to weld, diameter of conductor, and time to weld were varied in the experiments. The Taguchi method was used to design the experiment in this investigation. Analysis of covariance was used to explore the consequence of process settings on joint strength. Weld-current and electrode force were determined to be highly effective parameters on joint strength using the ANCOVA approach, however electrode OD and weld-time were less effective process characteristics. For managing joint strength, weld-current was nearly 2 times more critical than the 2-ranking element namely force of electrode, according to the findings.

For 304L electric resistance spot welded specimens, Dursun Ozyurek [3] studied the impact of the principal welding parameter such as current required to weld on quality of the weld bead and joint such as advents on the surface, size of the nugget, depth of penetration, interior weld line discontinuities, and strength. The upshot of different weld airs on the obstruction welding spot of 304-L treated steel is completely investigated. The best welding boundary for the most prominent joint strength was found to be a $9 \mathrm{kA}$ weld current. Because of the development of piece size, the malleable shear load with standing capacity of weldments improves with expanding input of heat identified with current required to weld. For 7 and $9 \mathrm{kA}$ weld flows, the pliable load withstanding capacity of welded materials shaped in nitrogen climate was observed to be advanced than that of weldments acquired in the ordinary environment. The roughening of the micro and macro structure of the weld lump and heat affected zone was created by an increment in heat input because of current.

P. Marashi [4] examined and analysed the failure behavior of low carbon ferrous and austenitic stainless ferrous dissimilar resistance weldments. Because of their differing resistance of electricity and heat conductivity, an asymmetric fusion-zone was discovered. With respect to peak current load and captivation of energy, size of fusion-zone and modes of failure were the most vital aspects in the quality of the weld, which were regulated by welding settings such as current required to weld, time to weld, and tangential force applied by the electrode.

Oscar Martn [5] explored the quality of a 304 austenitic stainless steel resistance spot welding joint based on its tensile shear load bearing capacity (TSLBC). Weld-time, weldcurrent, and force of electrode were the process parameters examined in this study (EF). The size of the nugget in the weld expands at the outlay of temperature input, which upsurges with cumulative weld-current and weld- time, according to this research. As a result, TSLBC rises initially as weld-current and weld-time rise. Excessive weld-current and duration of welding, on the other hand, cause molten metal to be ejected, lowering TSLBC. The hardness standards of the weld nugget was greater than those of the heat affected zone and base metallics due to hardening of strain generated through EF holding-time, as evidenced by the occurrence of slip regions in the cast austenite micro structure of the nugget developed during the welding.

\section{Taguchi Method}


The Taguchi method is used to optimize a process's process parameters in order to produce a high-quality response at a low cost. When the number of process parameters grows, a great number of experiments must be performed. Furthermore, it will result in increased costs and the use of more time. To tackle this challenge, the Taguchi technique employs an orthogonal array design of experiments, which allows researchers to inspect the consequence of all process constraints with a minor quantity of tests.

The difference between the experimental and desired values was then calculated using a loss function. The entire loss function's value has been converted into signal-to-noise (S/N) ratio. The data obtained for tests was analysed using signal-to-noise ratio, which could aid designers in quickly determining the best combination of parameters. In the examination $\mathrm{S} / \mathrm{N}$ ratio, 3 sorts of eminence criteria are typically used: the minimum-the-better, the maximumthe-better, and the normal-the-better. Based on $\mathrm{S} / \mathrm{N}$ study, $\mathrm{S} / \mathrm{N}$ ratio for each level of process constraints was calculated. A higher $\mathrm{S} / \mathrm{N}$ ratio refers better quality characteristics regardless of the type of quality attribute. As a result, the level of process parameters with the largest $\mathrm{S} / \mathrm{N}$ ratio is the best. In addition, ANOVA was used to determine the importance of each factors of the process. The percentage contribution of a parameter's influence on the response can be estimated using ANOVA.

\section{Experimentation Details}

The specimens were prepared by cutting the AISI 304 Stainless Steel sheet into suitable dimensions as per ISO 14273:2001 [6] standard. The dimensions were length $105 \mathrm{~mm}$, width $45 \mathrm{~mm}$ thickness $1 \mathrm{~mm}$ and overlap length of 35 between two specimens. Chemical composition of AISI Stainless Steel 304 is given in the Table 1.

Copper was used as the electrode material, which was fabricated in to truncated conical shape with varying its tip diameter, as the tip diameter also was a process parameter. Each electrode was replaced with new electrode after the welding of each specimen to avoid the effect of damage on the tip of the electrode.

Table1.ChemicalcompositionofAISIStainlessSteel

\begin{tabular}{|l|l|l|l|l|l|l|l|l|l|}
\hline Content & $\mathrm{Fe}$ & $\mathrm{C}$ & $\mathrm{Cr}$ & $\mathrm{Ni}$ & $\mathrm{Mo}$ & $\mathrm{Mn}$ & $\mathrm{Si}$ & $\mathrm{W}$ & $\mathrm{S}$ \\
\hline Value & $70.15 \%$ & $0.034 \%$ & $18.09 \%$ & $8.3 \%$ & $0.33 \%$ & $1.83 \%$ & $0.22 \%$ & $0.013 \%$ & $0.003 \%$ \\
\hline
\end{tabular}

\section{A. Selectionoffactors}

Three welding parameters, namely current required to weld, time to weld, and diameter of electrode, were selected with three levels in this investigation, as indicated in Table 2. The Taguchi L9 orthogonal array was used in the experimental experiments. Figure 1 depicts the spot welded specimens. The welded specimens were tensile tested in a universal testing machine with a traverse speed of $2 \mathrm{~mm} / \mathrm{min}$ after welding. Table 3 shows the experimental data obtained following tensile load testing.

Table2.Processfactors andlevels 


\begin{tabular}{|c|c|l|l|l|}
\hline S.No & Processfeatures & 1 & 2 & 3 \\
\hline 1 & $\begin{array}{c}\text { Current } \\
\text { required to } \\
\text { weld(A) }\end{array}$ & 2400 & 2800 & 3200 \\
\hline 2 & $\begin{array}{c}\text { Time to } \\
\text { weld(Sec) }\end{array}$ & 2 & 3 & 4 \\
\hline 3 & $\begin{array}{c}\text { Diameter of } \\
\text { the electrode } \\
\text { (mm) }\end{array}$ & 3.5 & 4.5 & 5.5 \\
\hline
\end{tabular}

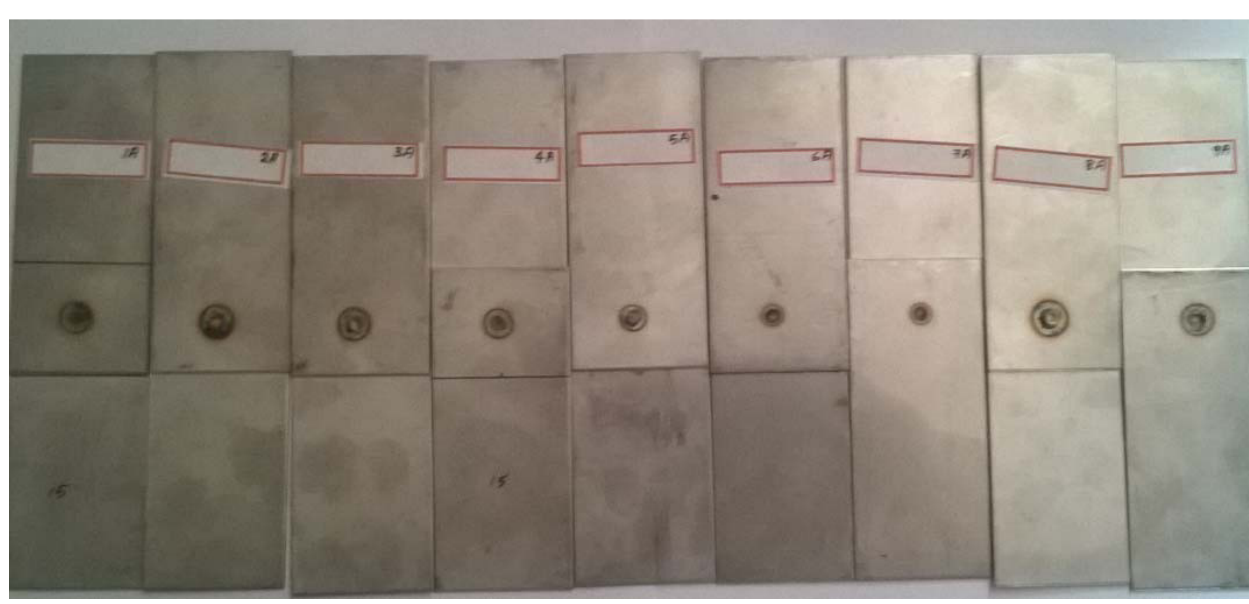

Fig1.Spotweldedspecimens

Table3.ExperimentalResultsofTensileLoadTesting

\begin{tabular}{|c|c|c|c|c|c|}
\hline \multirow[b]{2}{*}{$\begin{array}{l}\text { SerialNum } \\
\text { ber }\end{array}$} & \multicolumn{3}{|c|}{ ProcessParameters } & \multirow{2}{*}{$\begin{array}{l}\text { Tensile } \\
\quad \operatorname{Load}(\mathrm{N})\end{array}$} & \multirow[b]{2}{*}{ S/NRatio } \\
\hline & $\begin{array}{l}\text { WeldingCurrent } \\
\text { (A) }\end{array}$ & $\begin{array}{l}\text { WeldingTime } \\
\text { (sec) }\end{array}$ & $\begin{array}{c}\text { Electrode } \\
\text { Diameter }(\mathrm{mm})\end{array}$ & & \\
\hline 1 & 2400 & 2 & 3.5 & 6567 & 76.34 \\
\hline 2 & 2400 & 3 & 4.5 & 7169.5 & 77.11 \\
\hline 3 & 2400 & 4 & 5.5 & 5772 & 75.23 \\
\hline 4 & 2800 & 2 & 5.5 & 6469 & 76.22 \\
\hline 5 & 2800 & 3 & 3.5 & 8080.5 & 78.15 \\
\hline 6 & 2800 & 4 & 4.5 & 6165 & 75.8 \\
\hline 7 & 3200 & 2 & 4.5 & 8395 & 78.48 \\
\hline 8 & 3200 & 3 & 5.5 & 8075 & 78.14 \\
\hline
\end{tabular}




\begin{tabular}{|l|l|l|l|l|l|}
\hline 9 & 3200 & 4 & 3.5 & 8719 & 78.81 \\
\hline
\end{tabular}

\section{B.Signal to Noise (S/N) Ratio}

The term "signal" in the Taguchi technique refers to the desired value for output characteristics, while "noise" refers to the unwanted value for output characteristics. The goal of the $\mathrm{S} / \mathrm{N}$ ratio is to create procedures that are insensitive to various levels of noise. The output quality is always best when process parameters are set with the maximum $\mathrm{S} / \mathrm{N}$ ratio. As a result, the higher the $\mathrm{S} / \mathrm{N}$ ratio, the better the tensile load quality feature. Table 4 summarizes the $\mathrm{S} / \mathrm{N}$ ratio for each level of process settings, and Figure 2 depicts graph of $\mathrm{S} / \mathrm{N}$ ratio . The optimum level of process parameter for better tensile load has been determined from the graph. Table 4 demonstrates that the current required to weld is ranked number one, indicating that that the current has a noteworthy impact on the load due to tension of the welded specimen Welding duration and electrode diameter are the other two elements that contribute to a higher tensile stress. The primary effect plot for $\mathrm{S} / \mathrm{N}$ ratio is shown in Figure 2. It provides the ideal process parameter settings that will result in a higher output value. The optimum level of the process parameters in this process are $3200 \mathrm{~A}$ for the welding current, 3 seconds for the welding time, and $4.5 \mathrm{~mm}$ for the electrode diameter, according to the primary effect plot for the $\mathrm{S} / \mathrm{N}$ ratio graph.

Table4.Signaltonoiseratio

\begin{tabular}{|c|c|c|c|}
\hline Level & WeldingCurrent(A) & WeldingTime(Sec) & ElectrodeDiameter(mm) \\
\hline 1 & 76.23 & 77.02 & 77.77 \\
\hline 2 & 77.53 & 78.14 & 77.94 \\
\hline 3 & 78.82 & 77.42 & 76.87 \\
\hline Delta & 2.59 & 1.12 & 1.08 \\
\hline Rank & 1 & 2 & 3 \\
\hline
\end{tabular}

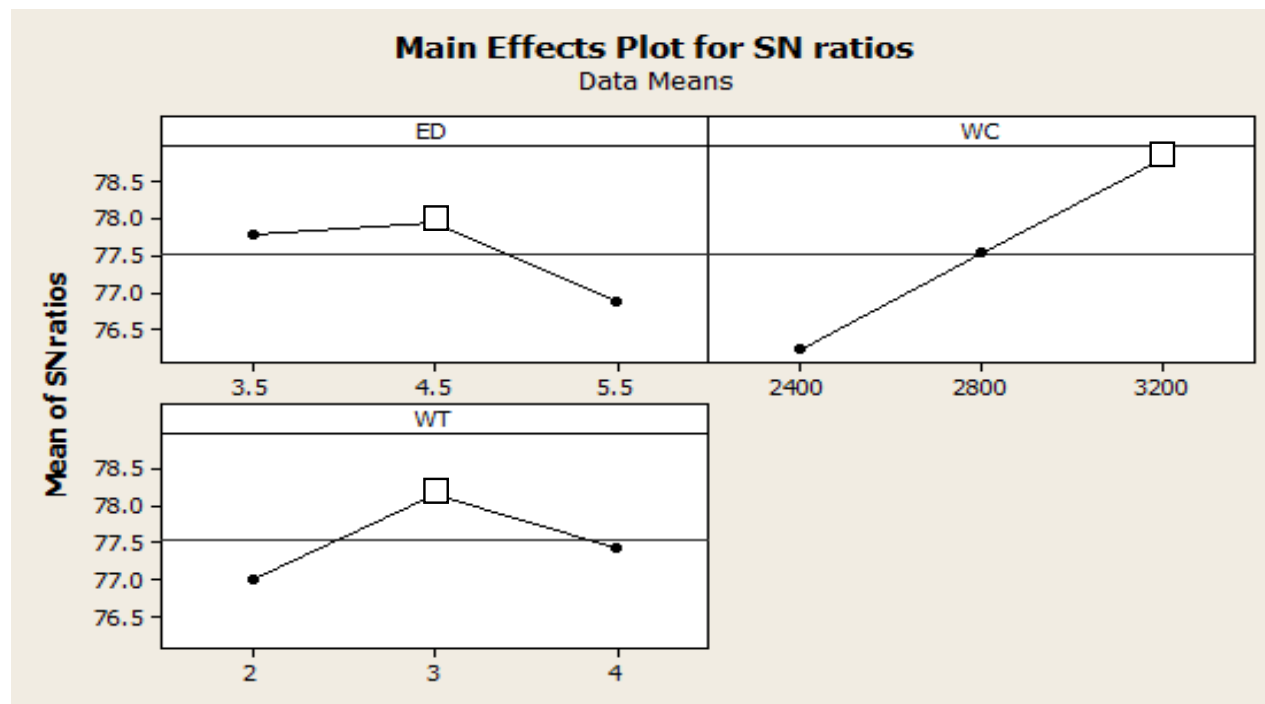

Signal-to-noise: Larger is better 
Fig.2 S/N ratio graph

\section{ANOVA}

It can be employed to govern the relative consequence of individual process characteristics and it is used to examine the impact of process factors on load due to tension. Result obtained by ANOVA is summarized in Table 5. The F-value also called variance ratio was obtained from minitab-16 software. This value shows the effect of process parameters over the response. A higher F-value signifies a larger impact and hence a higher contribution over the response. In this study confidence was selected as $95 \%$. According to this study, current required to weld, time to weld, and diameter of the electrode were the most beneficial process parameters in terms of tensile load. Percentage of influence of each factors of the process on load due to tension was found out and is shown in Table 5. For a factor with higher percentage of contribution on tensile load indicates a small variation in that parameter will cause large variation in the output. According to this, welding current (70.9 percent) was discovered to be the most important parameter determining the tensile load, followed by welding duration (13.4 percent) and electrode diameter (10.8 percent).

Table5Results of ANOVA

\begin{tabular}{|l|c|c|c|c|c|c|c|}
\hline \multicolumn{1}{|c|}{ Parameter } & $\begin{array}{c}\text { Degrees } \\
\text { offreedo } \\
\mathrm{m}\end{array}$ & $\begin{array}{c}\text { Sequential } \\
\text { Sum of } \\
\text { squares }\end{array}$ & $\begin{array}{c}\text { Adjusted } \\
\text { Sum of } \\
\text { squares }\end{array}$ & $\begin{array}{c}\text { Adjusted } \\
\text { Mean } \\
\text { Square }\end{array}$ & F- index & P-index & Contribution \\
\hline $\begin{array}{l}\text { Welding } \\
\text { Current }\end{array}$ & 2 & 7443314 & 7443314 & 3721657 & 14.74 & 0.064 & 70.9 \\
\hline $\begin{array}{l}\text { Welding } \\
\text { Time }\end{array}$ & 2 & 1406367 & 1406367 & 703184 & 2.79 & 0.264 & 13.4 \\
\hline $\begin{array}{l}\text { Electrode } \\
\text { Diameter }\end{array}$ & 2 & 1129342 & 1129342 & 564671 & 2.24 & 0.309 & 10.8 \\
\hline Error & 2 & 504836 & 504836 & 252418 & & & 4.8 \\
\hline Total & 8 & 10483858 & & & & & 100 \\
\hline
\end{tabular}

\section{Results and Discussion}

To improve the process settings for ERSW of AISI 304 ferrous specimens of $1 \mathrm{~mm}$ thickness, Taguchi's design of experiments was systematically carried out in this work. Table 2 lists the process parameters and levels that were chosen. Table 3 shows the results of tensile load testing. The $\mathrm{S} / \mathrm{N}$ ratio was calculated using Minitab-16 software and is summarised in Table 4. From this table, it can be deduced that as welding current increases, so does tensile load. As a result, level 3 (3200 A) is the best of the three welding levels currently available. This is related to the production of huge weld nuggets as a result of the increased heat generated when the welding current increases. Level 2 (3 sec) for welding duration and level 2 
(4.5 mm) for electrode diameter were likewise chosen for the other two parameters. The result of ANOVA was summarized in Table 5. From the Table 5, it was found that welding current was the most influencing parameter on weld strength, followed by welding time and electrode diameter.

\section{Conclusion}

Based on the investigation results, the conclusion points are listed below.

- The parameters which affect the ERSW of AISI 304 ferrous steel were studied. The optimum process parameter combination for maximizing the weld strength was identified.

- It was observed that welding current was the most influencing parameter which affecting the weld strength, followed by welding time and electrode diameter respectively.

- The factors such as current required to weld, time to weld and diameter of electrode contribute $70.9 \%, 13.4 \%$ and $10.8 \%$ respectively to the variation observed in the tensile load.

- The optimum process parameter combination for achieving maximum weld strength were current required to weld - 3200 Ampere, time to weld - 3 second and diameter of electrode $-4.5 \mathrm{~mm}$ respectively.

\section{References}

[1] PrasanthkumarVK,NithinVenkatraman,NSMahesh, Kumarswami, "Process Parameter SelectionforResistanceSpotWeldingThroughThermalAnalysis of 2mm CRCA Sheets",Procedia MaterialsScience,2014,369-378.

[2] Ugur Esme,"Application of Taguchi Method theOptimisationofResistanceSpotWelding(RSW)Process", TheArabianJournalofScienceandEngineering, 2 009, Volume34,Number2B.

[3] DursunOzyurek, "An effect of weld current and weldatmosphereontheresistancespotweldabilityof304L austenitic stainless steel" Materials and Design29,2008,597-603.

[4] P. Marashi, M. Pouranvari, S.Amirabdollahian, A.Abedi,M.Goodarzi,"Microstructureandfailurebehavior of dissimilar resistance spot welds betweenlow carbon galvanized and austenitic stainless steels",Materials Science and Engineering A 480, 2008, 175180.

[5] Oscar Martín, Pilar De Tiedra, Manuel López, ManuelSan-Juan, Cristina García, Fernando Martín, YolandaBlanco, "Quality prediction of resistance spot weldingjoints of 304 austenitic stainless steel", Materials andDesign30,2009,68-77.

[6] Specimen dimensions and for shear testingresistancespot,seamandembossedprojectionwelds.ISO14273:2000

[7] Y.J. Chao, "Failuremode of spot welds: interfacialversus pullout", Science and Technology of WeldingandJoining,Vol.8 No2,2003. 